\title{
Im Blickpunkt: 100 Jahre „Allergie“
}

$\mathrm{n}$ der vorliegenden Ausgabe von Allergo Journal zeichnen Bergmann (S. 328) und Ring (S. 334) den Lebenslauf von Clemens von Pirquet, dem Vater des Begriffes „Allergie“, sowie die Meilensteine der Allergiegeschichte nach. Deutlich wird, dass die vergangenen 100 Jahre - ebenso wie in allen anderen Bereichen von Wissenschaft und Forschung - auch für Allergologie und klinische Immunologie exponentiell wachsende Kenntnisse über Grundlagen, Diagnostik und Therapie gebracht haben, an deren Beginn ein genialer Forscher und Kliniker stand - Clemens von Pirquet.

Sein Lebenslauf belegt, dass bereits um die Wende zum 20. Jahrhundert Mobilität für eine erfolgreiche wissenschaftliche Laufbahn erforderlich war und dass auf der anderen Seite des Atlantiks die europäische Forschung Beachtung fand - für von Pirquet mündend in einen Ruf an die Johns-Hopkins-Universität in Baltimore. Gleichzeitig belegen die Stationen seiner Laufbahn, dass es auch damals schon einen regen Austausch zwischen den Universitäten gab.

Von Pirquet war Pädiater und hatte, wie der Beitrag von Bergmann zeigt, ausgezeichnete wissenschaftliche und klinische Lehrer. Seine eigene Entwicklung macht jedoch deutlich, dass der Begriff des „Lehrers" ebenso damals wie heute nicht den Kern der Beziehung zwischen dem "Chef" und seinen Mitarbeitern trifft - die Ideen von Pirquets waren ganz eigenständig.

Es war aber das Umfeld, das seine Entwicklung zweifellos begünstigte. Die Wiener Universität hatte in der zweiten Hälfte des 19. Jahrhunderts eine Spitzenstellung erlangt und eine Reihe bedeutender Mediziner berufen, wie den Anatomen Hyrtl, den Pathologen Rokitansky, den Dermatologen Hebra und den Chirurgen Billroth. Trotz aller politischen und sozialen Probleme war Wien damals einer der Brennpunkte der Welt. Hier studierte die Elite des Habsburger Reiches. Hier arbeiteten die Begründer der Psychoanalyse, Freud und Adler, der Otologe Robert Bárány, der Psychiater Julius Wagner-Jauregg und der Immunologe und Entdecker der Blutgruppen Karl Landsteiner. Die Wirtschaft florierte. In der Musik, der Literatur und in der bildenden Kunst war Wien weltweit führend. Nicht auf allen Gebieten war Wien jedoch fortschrittlich: Erst am 3. September 1900 wurden Frauen in Österreich zum Medizinstudium zugelassen.

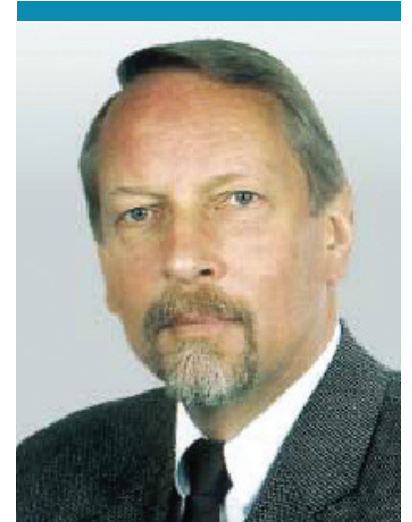

Prof. Dr. Gerhard SchultzeWerninghaus, Abteilung für Pneumologie, Allergologie und Schlafmedizin, BG-Kliniken Bergmannsheil - Universitätsklinik, Bochum

Das Umfeld ist der entscheidende Faktor für die Entstehung von hochqualifizierter Forschung. Und so war von Pirquet zweifellos begünstigt, den Allergiebegriff gerade in Wien zu prägen. Dass seine Definition des Allergiebegriffs als „Zustandsänderung, die der Organismus durch die Bekanntschaft mit irgend einem organischen, lebenden oder leblosen Gifte erfährt", die er auf Beobachtungen bei Infektionskrankheiten stützte, mit unserem

„Das Umfeld ist der entscheidende Faktor für die Entstehung von hochqualifizierter Forschung. “ übereinstimmt, hat den Siegeszug der „Allergie“ nicht beeinträchtigen können.

Die Allergologie der Wiener Universität hat in den vergangenen Jahrzehnten erfolgreich an die Glanzzeiten vor 100 Jahren angeknüpft. Aufgrund der Initiative von Prof. Dr. Dietrich Kraft ist in Wien einer der weltweit führenden Allergieschwerpunkte entstanden. Die Teilnehmer des großartig organisierten Europäischen Allergiekongresses vom 10.-15. Juni 2006 unter der Präsidentschaft von Prof. Dr. Rudolf Valenta haben sich davon überzeugen können.

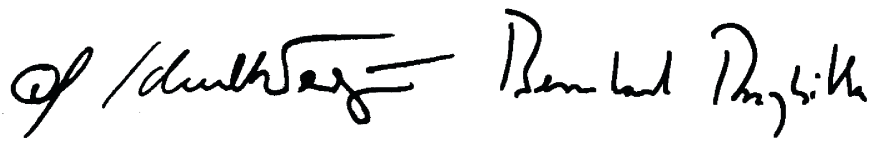

Prof. Dr. G. Schultze-Werninghaus Prof. Dr. B. Przybilla 